\section{Diabetes mellitus in ankylosing spondylitis}

Ankylosing spondylitis is a systemic inflammatory disease which always influences the spine joints. The association between ankylosing spondylitis and multiple systemic comorbidities has been well assessed. ${ }^{12}$ Recently, one meta-analysis conducted by Mathieu et al published in Annals of the Rheumatic Diseases reported that persons with ankylosing spondylitis were significantly associated with increased risks of myocardial infarction and stroke when compared with controls (risk ratio $=1.44$ for myocardial infarction, and risk ratio $=1.37$ for stroke). ${ }^{3}$ Mathieu et al's research is well performed and informative to the readers.

Diabetes mellitus is a well-established risk factor for myocardial infarction and stroke. One cross-sectional study reported that $13.64 \%$ of persons with ankylosing spondylitis had diabetes mellitus. ${ }^{4}$ We make a rational hypothesis that diabetes mellitus could be involved in the association between ankylosing spondylitis and myocardial infarction and stroke. In order to add updated concepts to support the findings of Mathieu et al's research, a preliminary nationwide cohort study was conducted to examine whether there is a link between ankylosing spondylitis and diabetes mellitus by using the 2005-2012 database of the Taiwan National Health Insurance Program with 23 million persons living in Taiwan. ${ }^{56}$ Persons ages $20-84$ years who had a new diagnosis of ankylosing spondylitis were assigned as the ankylosing spondylitis group based on International Classification of Diseases, Ninth Revision code (ICD-9 code 720.0). For every person with ankylosing spondylitis, four sex-matched and age-matched persons without a diagnosis of ankylosing spondylitis were selected as the non-ankylosing spondylitis group. The main outcome was a new diagnosis of diabetes mellitus (ICD-9 code 250). Table 1 illustrated that at the end of the cohort study, the overall incidence of diabetes mellitus was 1.21-fold higher in the ankylosing spondylitis group than in the non-ankylosing spondylitis group (1.43 vs 1.19 per 100 person-years, $95 \%$ CI 1.02 to $1.43, \mathrm{p}=0.025)$. As stratified by sex, the incidences of diabetes mellitus were all higher in the ankylosing spondylitis group than in the non-ankylosing spondylitis group, but only the male group reached statistical significance $(p=0.033)$.

In this preliminary study, persons with ankylosing spondylitis had a higher incidence of diabetes mellitus when compared with those without ankylosing spondylitis. Although the underlying mechanism regarding the association between ankylosing spondylitis and diabetes mellitus is beyond the scope of this study, surveillance bias contributing to a positive association cannot be ruled out. That is, persons with ankylosing spondylitis might receive frequent clinical care, such as periodically checking blood glucose. Then, diabetes mellitus, which usually cannot be early identified among persons without ankylosing spondylitis, is incidentally identified among those persons with ankylosing spondylitis. We suggest that more well-constructed studies are needed to determine whether there is a causal relationship between ankylosing spondylitis and diabetes mellitus.

Many unhealthy lifestyle habits have been found to be associated with increased risk of diabetes mellitus, including unhealthy dietary pattern, decreased physical activity, sedentary lifestyle, and smoking. ${ }^{78}$ From a view of preventive medicine, we suggest that physicians who take care of persons with ankylosing spondylitis should consider aggressive modification of unhealthy lifestyle habits to reduce the risk of diabetes mellitus. Then, these persons might have a chance to further reduce the risks of myocardial infarction and stroke.

\section{Kuan-Fu Liao, ${ }^{1,2}$ Yu-Hung Kuo, ${ }^{3}$ Shih-Wei Lai ${ }^{4,5}$}

${ }^{1}$ College of Medicine, Tzu Chi University, Hualien, Taiwan

${ }^{2}$ Division of Hepatogastroenterology, Department of Internal Medicine, Taichung Tzu Chi Hospital, Taichung, Taiwan
${ }^{3}$ Department of Research, Taichung Tzu Chi Hospital, Taichung, Taiwan

${ }^{4}$ College of Medicine, China Medical University, Taichung, Taiwan

${ }^{5}$ Department of Family Medicine, China Medical University Hospital, Taichung, Taiwan

Correspondence to Dr Shih-Wei Lai, Department of Family Medicine, China Medical University Hospital, No 2, Yu-De Road, Taichung 40402, Taiwan; wei@mail.cmuh.org.tw

Contributors K-FL and S-WL contributed to the conception of the article, initiated the draft of the article and has approved the final draft submitted. Y-HK conducted data analysis.

Funding The authors have not declared a specific grant for this research from any funding agency in the public, commercial or not-for-profit sectors.

Competing interests None declared.

Patient consent for publication Not required.

Ethics approval Insurance reimbursement claims data used in this study were available for public access. Patient identification numbers were scrambled to ensure confidentiality. This study was approved by the Research Ethics Committee of China Medical University and Hospital in Taiwan (CMUH-104-REC2-115).

Provenance and peer review Not commissioned; internally peer reviewed. (c) Author(s) (or their employer(s)) 2021. No commercial re-use. See rights and permissions. Published by BMJ.

\section{Check for updates}

To cite Liao K-F, Kuo Y-H, Lai S-W. Ann Rheum Dis 2021;80:e134.

Received 26 August 2019

Accepted 30 August 2019

Published Online First 6 September 2019

\section{SLinked}

- http://dx.doi.org/10.1136/annrheumdis-2019-216249

Ann Rheum Dis 2021;80:e134. doi:10.1136/annrheumdis-2019-216221

\section{ORCID iD}

Shih-Wei Lai http://orcid.org/0000-0002-7420-1572

\section{REFERENCES}

1 Chou C-H, Lin M-C, Peng C-L, et al. A nationwide population-based retrospective cohort study: increased risk of acute coronary syndrome in patients with ankylosing spondylitis. Scand J Rheumatol 2014;43:132-6.

2 Lai S-W, Lin C-L. Association between ankylosing spondylitis and chronic obstructive pulmonary disease in Taiwan. Eur J Intern Med 2018;57:e28-9.

3 Mathieu S, Soubrier M. Cardiovascular events in ankylosing spondylitis: a 2018 metaanalysis. Ann Rheum Dis 2019;78:e57

4 Garip Y, Eser F, Guler T, et al. Comorbidity profiles among patients with ankylosing spondylitis. Marmara Medical Journal 2016;29:23-8.

5 Ministry of Health and Welfare Taiwan. 2016 Taiwan health and welfare report. Available: http://www.mohw.gov.tw [Accessed 1 Aug 2019].

6 Lai S-W, Lin C-L, Liao K-F. Population-Based cohort study examining the association between weight loss and pulmonary tuberculosis in adults. BioMedicine 2018;8:12-16.

7 Nguyen CT, Pham NM, Lee AH, et al. Prevalence of and risk factors for type 2 diabetes mellitus in Vietnam. Asia Pac J Public Health 2015;27:588-600.

8 Bellou V, Belbasis L, Tzoulaki I, et al. Risk factors for type 2 diabetes mellitus: an exposure-wide umbrella review of meta-analyses. PLoS One 2018;13:e0194127.

\begin{tabular}{|c|c|c|c|c|c|c|c|c|c|c|}
\hline \multirow[b]{2}{*}{ Variable } & \multicolumn{4}{|c|}{ Ankylosing spondylitis } & \multicolumn{4}{|c|}{ Non-ankylosing spondylitis } & \multirow[b]{2}{*}{ Incidence rate ratio $(95 \% \mathrm{Cl})^{*}$} & \multirow[b]{2}{*}{$P$ value } \\
\hline & $\mathrm{N}$ & Event & Person- years & Incidence & $\mathrm{N}$ & Event & Person- years & Incidence & & \\
\hline All & 2757 & 164 & 11447 & 1.43 & 11028 & 972 & 81955 & 1.19 & 1.21 (1.02 to 1.43$)$ & 0.025 \\
\hline \multicolumn{11}{|l|}{ Sex } \\
\hline Male & 1633 & 99 & 6890 & 1.44 & 6532 & 552 & 48496 & 1.14 & 1.26 (1.02 to 1.56$)$ & 0.033 \\
\hline Female & 1124 & 65 & 4557 & 1.43 & 4496 & 420 & 33459 & 1.26 & 1.14 (0.88 to 1.48$)$ & 0.338 \\
\hline
\end{tabular}

Incidence: per 100 person-years.

*Incidence rate ratio: ankylosing spondylitis versus non-ankylosing spondylitis ( $95 \% \mathrm{Cl})$. 